\title{
Sequential duodeno-biliary double metal stenting in Mutignani type I obstruction facilitated by stentfixOTSC ${ }^{\circledR}$ anchoring device
}

\author{
Vincent Zimmer ${ }^{\mathrm{a}, \mathrm{b}}$ \\ Marienhausklinik St. Josef Kohlhof, Neunkirchen; Saarland University Medical Center, Homburg, Germany
}

\begin{abstract}
A 70-year-old male patient with a history of colorectal cancer presented with nausea, abdominal pain and jaundice. Imaging studies indicated diffuse peritoneal spread and lung metastases as well as intrahepatic biliary dilation. Laboratory assessment indicated marked cholestasis (bilirubin $6.8 \mathrm{mg} / \mathrm{dL}$, alkaline phosphatase 1,019 U/L). Conventional endoscopic retrograde cholangiopancreatography (ERCP) proved impossible due to a high-grade proximal duodenal bulb stricture (Fig. 1A) estimated at $20 \mathrm{~mm}$ axial length on fluoroscopy (not shown). Therefore, the patient first underwent gastroduodenal stenting using a 60x20-mm uncovered self-expanding metal stent (SEMS; Taewoong Medical; Fig. 1B). In order to facilitate timely through-the-stent ERCP (TTS-ERCP), stent fixation using the newly marketed dedicated anchoring device stentfixOTSC ${ }^{\circledast}$ (Ovesco Endoscopy) was used (Fig. 1C,D). As a derivative of the conventional over-the-scope clip (OTSC) platform, the device design is different in its brackets being bowed to the outside, and indentations in the application cap, both instrumental for better stent engagement [1]. Albeit careful attempts at same-session duodenoscope passage failed, the patient underwent successful TTS-ERCP the following day after full stent expansion with the papilla located more distally. Nonetheless, biliary access proved difficult but could be achieved by double guidewire cannulation with subsequent prophylactic pancreatic duct stenting. On the cholangiogram, an estimated $45-\mathrm{mm}$ long bile duct stricture emerged which was provided with an $80 \times 10-$ mm fully covered SEMS placed above the papilla ("inside stent") (Fig. 1D).

Stent anchoring is about to emerge as a new standard in gastrointestinal stent treatment, at least so when using covered stent technology. By contrast, although uncovered stents are in general less prone to stent migration, however,
\end{abstract}

aDepartment of Medicine, Marienhausklinik St. Josef Kohlhof,

Neunkirchen (Vincent Zimmer); ${ }^{b}$ Department of Medicine II, Saarland University Medical Center, Homburg (Vincent Zimmer), Germany

Conflict of Interest: None

Correspondence to: Dr. Vincent Zimmer, Department of Medicine, Marienhausklinik St. Josef Kohlhof, Klinikweg 1-5, 66539 Neunkirchen, Germany, e-mail: vincent.zimmer@gmx.de

Received 29 September 2020; accepted 6 October 2020; published online 4 January 2021

DOI: https://doi.org/10.20524/aog.2021.0569

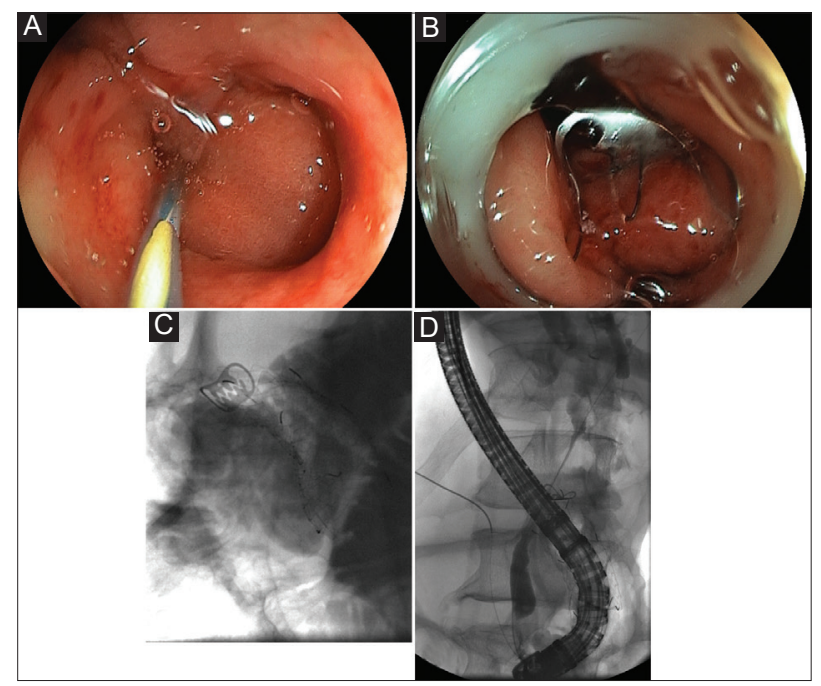

Figure 1 (A) Endoscopic visualization of the high-grade proximal duodenal bulb stricture with the cannula and guidewire already placed for subsequent gastroduodenal stenting. (B) The deployed stentfixOTSC ${ }^{\circledast}$ engaged to the proximal end of a $60 \times 20$-mm uncovered gastroduodenal self-expanding metal stent (SEMS). (C) Fluoroscopic demonstration of the newly placed SEMS with the stentfixOTSC ${ }^{\oplus}$ tightly attached (note brackets being bowed to the outside). (D) Successful through-the-stent endoscopic retrograde cholangiopancreatography (TTS-ERCP) with difficult biliary access (double guidewire technique) and a long stricture in the, bile duct provided with an 80x10-mm fully covered SEMS

in certain situations where mechanical forces may be high in newly deployed stents, such as in TTS-ERCP procedures, stent anchoring by the newly marketed stentfixOTSC ${ }^{\circledast}$ system may be instrumental to enhance procedural safety $[2,3]$.

\section{References}

1. Conio M, Savarese MF, Baron TH, De Ceglie A. A newly designed over-the-scope-clip device to prevent fully covered metal stents migration: a pilot study. TIGE 2020;22:167-171.

2. Zimmer V. Gastrointestinal: Utilization of a novel dedicated stent fixation clip device ("stentfix OTSC") for an umbrella-type cardia stent. J Gastroenterol Hepatol 2020;35:1466.

3. Perumpail RB, Muthusamy VR. Gastrointestinal stents: thinking outside the box. TIGE 2020;22:239-244. 